\title{
The Double Intentionality of Emotional Experience
}

\author{
Tom Cochrane
}

\begin{abstract}
I argue that while the feeling of bodily responses is not necessary to emotion, these feelings contribute significant meaningful content to everyday emotional experience. Emotional bodily feelings represent a 'state of self', analysed as a sense of one's body affording certain patterns of interaction with the environment. Recognising that there are two sources of intentional content in everyday emotional experience allows us to reconcile the diverging intuitions that people have about emotional states, and to understand better the long-standing debate between bodily feeling-based and appraisal-based theories of emotion.
\end{abstract}

\section{Introduction}

The goal of this article is to show that the average emotional experience contains two distinguishable sources of intentional content. One of these is the emotional awareness of the situation and the other is the bodily feeling. Given that it's fairly standard to think that emotions are representational states that generate bodily responses, this claim shouldn't really be very surprising. However, philosophers defending somatic views of emotions have typically wanted to unify the intentional content of emotions with bodily feelings as much as possible (e.g. Gunther 2004; Deonna and Teroni 2012; Barlassina and Newen 2013). A prominent example is Jesse Prinz's (2004) perceptual model. Prinz claims that we perceive emotional objects like 'danger' or 'offence' in virtue of registering bodily changes that are caused by dangers and offences. Thus according to Prinz, bodily feelings are the core constitutive feature of emotional experience.

The perceptual structure of Prinz's model has been criticised in detail elsewhere, and it is not my concern to rehash these criticisms. ${ }^{1}$ I will restrict myself here to a point about phenomenology. Prinz draws an analogy between perceiving dangers in virtue of feeling bodily changes and seeing colours in virtue of retinal activity. Yet unlike the case of retinal activity, our bodily changes are not phenomenally transparent. That is, bodily changes are not something we fail to notice on our path towards getting in contact with the external situation, but rather objects of distinct experience. It takes considerable philosophical ingenuity to deny the seemingly obvious fact that feeling something happening in your body is not the same as attending to a dangerous situation. Prinz has to say that having the bodily changes reveals emotional features that are not otherwise available. Thus he makes statements like 'we feel the offensiveness of external situations resonating through 
our flesh' (2004: 227). But while I find Prinz's statement attractive, on closer examination the metaphor of resonance suggests that we experience a resemblance between the feeling and the offensiveness of the situation. If so, this would entail that we already have independent access to the situational offence, obviating the necessity of bodily feelings.

At any rate, I will argue in this paper that we can display emotional awareness without the experience of bodily feelings. At the same time, there is something to be said for the claim that the bodily feelings capture emotional meaning in their own right. The bodily feelings we have when undergoing emotions are not simply patterns of bodily sensations. They feel decidedly appropriate to the situation. Other philosophers have picked up on this (e.g. Slaby 2012; Deonna \& Teroni 2012: 76-90), yet in my opinion the meaningful nature of bodily feelings has yet to be clearly understood. We must first recognise that we can have emotions without bodily feelings, and then provide an independent account of how bodily feelings acquire emotional meaning.

To argue for the double intentionality of emotional experience, in Section 2 of this paper I will present various reasons for thinking that we can have emotions without experiencing bodily feelings (though bodily responses may be necessary). However, I will also argue that some cases of mood show that bodily feelings can have emotional meaning in their own right. Then in Section 3 I will articulate the intentional richness of emotional bodily feelings. I will reject some accounts that appeal to associations between bodily feelings and particular external objects and instead suggest that feelings represent the capacity of the body for certain patterns of interaction with the environment. Finally in Section 4 I will argue that recognising the double intentionality of emotional experience helps us to understand the differing intuitions that people have about emotions more generally. Indeed, if I'm right about bodily feelings, there are significant implications for the longstanding debate within the philosophy of emotions between those who place bodily feelings central to emotions and those who emphasise situational appraisals. Once we allow that there may be two sources of intentional content in an emotional experience, both of which deliver significant emotional meaning, we have a novel way to reconcile the opposing sides of this debate. Both sides may have said something right about emotional intentionality, and are only wrong if they claim to have a complete picture of what is going on.

\section{Distinguishing Emotions and Bodily Feelings}

\subsection{Emotions without bodily feelings}

In his book on emotions, Peter Goldie (2000) describes the following case:

You are driving a car, and you see another car, out of control, approaching you on the wrong side of the road. You realise just what is going on, you see the danger to yourself and your passengers, and, with 
great speed and dexterity, you take the necessary evasive action. Then, when your car has finally come to a halt, you think with horror of just how close you were to death; you realise that you are bathed in a cold sweat, you see the whiteness of your knuckles as you still clench the steering wheel, and you feel your heart pumping. Looking back on the experience, you now agree that you were afraid whilst you were taking evasive action even though, you now can also say, you did not feel fear at that time. (2000: 62)

Goldie uses this example to distinguish between reflective consciousness of one's emotion, and a state of being 'unreflectively emotionally engaged with the world' (2000: 64). It is in this latter sense that he means that the driver has an emotion while not feeling fear. This seems right. Despite the driver's lack of awareness that he is undergoing an emotion, his understanding of the situation, his physiological responses and his behavioural reactions indicate that he is in an emotional state. Anyone observing him would judge that he is in a state of fear or panic.

What is significantly lacking in the driver case however is (at the time) any feeling of the bodily responses involved. So if we agree that the driver is having an emotion, we must accordingly reject James' (1884) claim that emotions should be identified with the feeling of bodily changes. We need not reject James' claim that some pattern of bodily changes is necessary for an emotion. Indeed, I agree with James that when we fully introspect on our emotional states, we always discern some bodily activity at work. But this is quite separate from claiming that we must experience our bodily changes when undergoing an emotion.

Now a Jamesian might respond to the driver case by suggesting that while reflective consciousness of bodily feelings may be lacking, this does not entail that unreflective feelings are also lacking. After all, James himself states, 'our own bodily position, attitude, condition, is one of the things of which some awareness, however inattentive, invariably accompanies the knowledge of whatever else we know' (1890: 242).

We can however adjust the case to definitely rule out non-reflective consciousness of feelings, without I think, undermining the claim that the driver undergoes an emotion. For let us suppose that the driver has a condition such that he is incapable of experiencing bodily feelings. That is, while the driver's bodily responses are monitored and guided at some sub-personal level, he suffers a condition analogous to blindsight such that this monitoring is inaccessible to conscious awareness. ${ }^{2}$ The consequence of such a condition would entail that the driver loses the capacity to become aware of his emotions in a certain way. He would lose an intuitive sense of the affordances offered by his body, and would probably have trouble understanding some of the ways in which emotions are described. But it seems that the most vital features of emotions would be retained. In particular, the bodily responses would retain their capacity to serve the interests of the subject in the ways that the bodily responses involved 
in emotions paradigmatically do. In the case described above, they protect the driver from the danger, regardless of whether or not he is able to experience those responses.

\subsection{Situational phenomenology}

An alternative way to respond to the driver case would be to give up the claim that emotions are necessarily conscious, yet still demand that when emotions are conscious they necessarily involve bodily feelings. Accordingly, this view would entail denying that the driver is having a conscious emotional experience. However, this denial does not seem to be tenable, since from the first-person perspective, there is much about the driver's conscious experience that is emotional in tone. His visual and auditory experiences of the oncoming car (including perhaps a mental image of the anticipated crash) are suffused with an awareness of the danger that the situation instantiates. Moreover, this awareness is no idle observation. It plays an indispensable role in guiding his behavioural response. So it seems fair to say that the driver is consciously aware of the situation in an emotional way.

Another way to put this point is that we should recognise the existence of distinctly emotional situational phenomenology. In support of this consideration, note all the ways in which we describe emotional experience without reference to bodily feelings. For example, we describe situations where everything seems to slow down or speed up, where the threat was looming menacingly, the world was spinning, other people seemed somehow distant, colours were more vivid or dulled, edges looked sharper or smoother, sounds were harsher, the assailant's weapon filled our attention, we could never forget the expression on his face and so on. These situation-focused experiences are comparable to the driver case in reflecting a pattern of saliencies that play an important role in guiding the individual's behavioural response. Note also that these experiences are implicitly subject-relating, since they involve the subject being oriented towards those features of the environment.

Once we recognise the existence of emotional situational phenomenology, one of the core motivations for thinking that bodily feelings are necessary to emotions is undermined. The motivating intuition seems to be that bodily feelings make a vital contribution to the evaluative nature of emotions. In particular, bodily feelings provide 'heat' or 'colour' to a cold appraisal of the situation. However, once we recognise the non-bodily phenomenology of emotions, we no longer need bodily feelings to add colour to a cold appraisal, and naturally, it would be question begging to simply assert that the driver's awareness must possess such colouring from bodily feelings to qualify as an emotion.

We can also undercut the appeal of emotional colouring by noting that bodily responses can contribute to the evaluative nature of emotions without being felt. Note that the intensity and suddenness of the driver's avoidant responses are appropriate to the imminent and potentially catastrophic nature of the threat at hand. In virtue of responding in an urgent, aversive manner, the bodily 
responses may be said to track the urgent and aversive nature of the target. In this sense, the combination of environmental awareness and appropriate bodily response delivers an intentional state that is functionally evaluative in nature. This is no mere disinterested recognition of the danger but an active engagement with it. So it looks like emotions can satisfy both regulative and evaluative functions without the aid of bodily feelings. This kind of responsiveness only requires an awareness of one's relationship with the environment.

\subsection{Emotion intentionality}

A final consideration against the necessity of feelings follows from the intentional content of emotions. Many philosophers think that our emotions are directed at particular objects (e.g. Deonna and Teroni 2012; Goldie 2000; Solomon 2007). This coheres with our ordinary way of saying 'I was afraid of crashing' or, 'I was happy about my promotion'. Yet it does not seem possible to discover such situational contents in the bodily feelings themselves. The only particular situational content that could be found in bodily feelings is the specific condition of the body, which is only rarely the object of an emotional state.

Now it may be that when consciously experiencing an emotion, the individual takes a further step in associating their bodily feeling with the particular object (this seems to be the move that both Goldie 2000 and Deonna and Teroni 2012 opt for, to be discussed below). But relying on such association would entail that there are occasions where bodily feelings are not associated the experience of the situation. Thus someone defending the essential role of bodily feelings in emotional experience would have to claim that the experience of the particular object only becomes emotional once the bodily feeling gets associated with it. However, the onus would be on the defender of such a view to explain why such an association is necessarily required, when the individual can seemingly perform the practical and evaluative roles of emotions without such associations, and when non-bodily-based emotional phenomenology is readily available.

While I endorse the view that emotions include a representation of the particular object, it is worth noting that the defender of the intentionality of bodily feelings may reach for an alternate view. They may claim that, despite our ordinary ways of talking, emotions are not at all about particular objects, but only formal objects such as 'danger' or 'the loss of something valued' (e.g. Lazarus 1991; Prinz 2004). Perhaps this kind of formal content can be captured by feelings. Indeed I want to allow that bodily feelings capture content that is somewhat generalised in nature, and will elaborate further on this idea below. But for now it is sufficient to note that bodily feelings are not necessary for emotions to track formal objects. We can appeal to a similar point that was made in 2.2. If the unfelt bodily responses combined with situational awareness are sufficient to show that the individual is sensitive, in an evaluative manner, to a particular object, then we can employ the same resources to say that the individual is sensitive to the formal qualities of the situation. We need only add that the sensitivity corresponds to certain types of object. ${ }^{3}$ 


\subsection{Moods}

The arguments presented so far seem sufficient to justify the claim that bodily feelings are not necessary for emotions. However this should not be taken to imply that feelings are unimportant features of ordinary emotional experience. On the contrary, I want to argue that bodily feelings can be distinctly emotional in nature and that in the average emotional experience they can play a very important role for the individual. So at this point, we must note that not only can there be emotions without bodily feelings but also that we can have emotional bodily feelings while lacking emotions about particular objects. These emotional bodily feelings are not emotions, strictly speaking, but I think it fair to include them within a broader category of emotional experience (or affective experience, if one prefers).

Consider the following scenario: Over the course of a day, someone steals your parking space just as you are about to drive into it, you find you've run out of coffee, your computer crashes before you can save an important document, you mislay your wallet and must spend half an hour searching for it, and your boss imposes a tedious, but urgent task upon you. In each case you feel some degree of frustration, and indeed unfortunate events seem to be piling up, such that by the time you trip over a kink in the rug on the way out, you've just about had enough. Since you resolve each of these individual incidents, you manage to put them out of your mind. However you return home with a pervasive bodily feeling of discomfort; almost as if you had been repeatedly pushed about or prodded. In the state you are in, the slightest provocation is liable to enrage you.

Typically, we would describe what you feel at the end of day as a certain kind of mood, though the term 'mood' glosses over different phenomena that I think should be distinguished. In the case above, it seems that the repeated trigger of a certain emotional response causes our bodily systems to linger in a certain configuration that is highly congruent with the further arousal of similar emotional responses. It is not hard to imagine why such lingering might be useful, even when the particular situations have been put out of mind. Any creature inhabiting an environment that repeatedly calls for a certain adaptive response, such as fleeing or fighting, will more quickly or efficiently initiate that response if their bodily configurations are already in the relevant state. Thus it is not surprising that a good deal of empirical evidence (surveyed in a meta-review by Yiend 2009) suggests that we display biases towards recollecting or interpreting events in ways congruent with a previously induced emotional state. ${ }^{4}$

Of particular interest here, however, is that absent any particular object at which one's bodily response is directed, the individual experiences a bodily feeling that conveys a rather general sort of emotional attitude. The individual reports that he or she feels frustrated or depressed or anxious. I will have more to say about the content of such feelings in Sections 3.2 and 3.3 below. In particular, we have yet to determine whether these feelings have distinctive intentional content, and if so, how this is to be characterised. But for now it appears that we can be both reflectively conscious of such emotional bodily feelings as well as non-reflectively 
guided by them in our interpretations of events, while lacking the emotional experience of any particular object.

Alongside moods, long-term affective states such as depression, generalised nervousness or incorrigible enthusiasm display similar sorts of cognitive biases and general attitudes. Importantly for me, while such attitudes are not directed at any particular object, they seem characteristically to involve certain patterns of bodily feeling; one is chronically disposed to feel heavy and languid in the case of depression, tense and jittery in the case of nervousness, energetic and restless in the case of enthusiasm. It is likely that such long-term states arise from stable reconfigurations of the psycho-biological system, which are then reinforced by specific emotional appraisals. I will have more to say about whether emotional bodily feelings can lack prior appraisals of a particular object in Section 3.5 below. For now it is sufficient to observe that there are at least some long-term affective states that would intuitively be described as emotional while the individual can honestly report that they are not depressed, anxious or enthusiastic about any particular thing.

Perhaps it might be complained that the cases of mood I have described still involve an emotion about a particular object, just one that is unconscious, or non-reflectively grasped. The onus is on my opponent to prove the need for such appraisals, particularly when we have plausible psycho-biological routes towards the cases described that obviate the appeal to unconscious or implicit particular objects. It's also possible to experientially differentiate the cases I have described from ones where we sense a hidden object or reason. In such cases, subtle cues manage to trigger a bodily response while we are unaware of their target. We say to ourselves 'something just doesn't feel right' or, 'for some reason, I feel optimistic about today'. Crucially, we are aware of undergoing an emotion and that it probably has an object. And in the absence of any conscious recognition of this object, we can attend to the bodily feeling, and wonder what justifies it. This sort of detail does not attend the other cases of moods I have described, so there isn't much motivation to suppose that some unconscious appraisal of a particular object is in operation in those cases.

\subsection{Reflective emotional consciousness}

Taken together, the cases presented above indicate that there is a double dissociation between the emotional experience of bodily feelings and the emotional experience of particular situations. Either can occur without the other. This distinction also cuts across the distinction between reflective and non-reflective consciousness. The case of moods indicates that we can have either reflective or non-reflective consciousness of bodily feelings while lacking any concurrent emotional experience of a particular situation. The driver case meanwhile suggests that we could have either reflective or non-reflective emotional experience of particular situations while entirely lacking bodily feelings (even where bodily responses are considered necessary to emotions). 
In general, it is easier to make the distinction between the emotional experience of situations and the experience of bodily feelings in scenarios characterised by non-reflective consciousness. This is because reflective consciousness of an emotion tends (though not necessarily) to bring with it attention to one's internal state that will deliver the experience of bodily feelings. The distinction between bodily feelings and the emotional experience of situations can, however, be appreciated where both are reflectively experienced. Consider for instance the following case: I once received an automated phone call from the bank informing me of a number of suspicious recent transactions that had emptied my account of several thousand pounds. As I was impotently forced to listen to the machinetoned voice intoning these worrying transactions, many of the same reactions that accompanied the driver case-muscle tension, raised heart rate, a cold sweatwere triggered. Constrained as I was, it was easy for me to attend to my bodily feelings in isolation from my awareness of the situational threat. In particular, it wasn't simply that I could pick out my bodily responses as an atomised set of distinct components. I could attend to the overall bodily pattern or gestalt, its general anxious or frustrated character, in isolation from the particular situation that the responses were aimed at.

In conceptually sophisticated cases of emotion especially, we are often inhibited from acting in the ways that our bodies are pushing us to behave (one does not flee the phone call). ${ }^{5}$ In such cases, we often form evaluative attitudes towards our bodily feelings that are distinct from the evaluative stance taken by the emotion itself. If one is disconsolate after being rejected by a lover for instance, one's body may seem to ache for renewed contact, even while one wishes to rid oneself of such troublesome feelings. Similarly, panic attacks seem to be cases where an exaggerated fear response is triggered by a relatively innocuous worry. Sufferers of this condition report that the panic response itself becomes the object of fear. These cases again indicate our ability to direct attention distinctly towards our bodily feelings.

\section{Meaningful Feelings}

So far, I have suggested that bodily feelings are not necessary for emotions. However, bodily feelings can provide additional content that conveys a sort of general emotional gestalt or attitude. These claims seem to accord bodily feelings a strictly peripheral role in emotions. Moreover, some might claim that the cases of mood and long-term affective conditions described in the previous sections hardly count as emotional in their own right. They lack intentional content that reflects the world-oriented status of the individual; they are mere patterns of bodily sensation. The goal of this section is to deny that emotional bodily feelings are mere patterns of sensation, or simply conscious experiences of a certain aspect of the emotional process. Bodily feelings also convey emotional meaning in their own right.

Consider a strong bodily feeling of fear. It seems plain that this bodily feeling, in its own right, powerfully and vividly conveys a sense of vulnerability. Similarly, if 
one feels sad upon the occasion of a loved one's death, the property of loss is bound up in the bodily feel of the emotion such that it is natural to say 'I feel loss... I really feel like something vital is missing'. These kinds of report indicate that the feelings themselves possess intentional content. At the same time, there does not seem to be anything intrinsically vulnerable about the feeling of vulnerability, or loss-like about the feeling of loss. In themselves they are patterns of fluttering sensations. So it seems that our bodily feelings are experienced as possessing content that reaches beyond the sensation itself. That is, emotional bodily feelings are experienced as representational, rather than immediate and incorrigible presentations of bodily sensation. The concern of this and the next few sections is to provide a coherent articulation of just what it is that these bodily feelings could represent.

\subsection{Association-based accounts}

Since we (normally) already have an emotional representation of the particular object, we may prefer to fold the intentionality of the bodily feeling into that. One might say that we experience the particular object of one's emotion with the bodily feeling, in the sense that the bodily feeling accompanies, but is strictly speaking separable from one's emotional experience of the situation. This seems to be Peter Goldie's approach. Like me, Goldie distinguishes between the intentionality of the emotion and the intentionality of the bodily feeling, and initially states that the latter is directed at the overall condition of the body (2000: 51). However, in recognition of the meaningful quality of bodily feelings, he suggests that feelings display 'borrowed intentionality' (2000: 54-57). They become 'united in consciousness' (2000: 55) with the awareness of the object. As best as I can understand this, borrowed intentionality amounts to an association made by the subject between the bodily feeling and their awareness of the particular, external object of the emotional state. In virtue of this association, our bodily pangs seem to be about the situation.

While I agree with Goldie that everyday emotional experience may blend the awareness of the body with the awareness of the situation, I think that the notion of borrowed intentionality fails to acknowledge the special contribution that bodily feelings make to emotional experience. First and foremost, bodily feelings represent the condition of one's body. The idea that bodily feelings borrow intentionality from the awareness of the situation depreciates the immediacy with which they convey information about the body.

A somewhat similar position to Goldie's is presented by Deonna and Teroni (2012) (though they may not welcome my saying so). Deonna and Teroni are keen to emphasise that emotions are directed at particular objects rather than formal objects (2012: 77-78). ${ }^{6}$ But they also claim that emotions are 'felt bodily stances' (2012: 76). To explain this, Deonna and Teroni write, 'we should conceive of emotions as distinctive types of bodily awareness, where the subject experiences her body holistically as taking an attitude towards a certain object' (2012: 79). The notion of 'attitude' is important for Deonna and Teroni because they don't want to say the bodily responses are representational states. Rather the response can be 
understood as a mode or manner of awareness. Here Deonna and Teroni are drawing on the proposition-attitude distinction that is common in functionalist accounts of mental states (2012: 90). That is, just as one can take differing attitudes towards the same proposition (e.g. believe it, desire it, intend it) so one can take differing emotional attitudes towards the same object. So the snarling dog can be approached fearfully, or joyfully or despairingly, depending on the response it triggers.

On Deonna and Teroni's view, the emotion is triggered by what they call the 'cognitive base'. This is the perception, imagination or inference that picks up on certain qualities of the particular object. It is not the emotion itself. But if the cognitive base is not the emotion, it is unclear what part of the emotion itself coveys its intentional object. The bodily feeling alone cannot capture it, as I argued in Section 2.3. So if Deonna and Teroni want to say that emotions have particular intentional objects (which they clearly want to do), they cannot fully identify emotions with bodily feelings. Instead, it looks like some association or projection of the bodily feeling onto the particular object is required, as in Goldie's theory. Indeed, this seems to fit with the way they say that the subject experiences her body as taking an attitude towards an object. Yet if this is Deonna and Teroni's view, they need to explain how the particular object gets mentally united with the bodily feeling (if at all). Otherwise, it is uncertain what determines the direction of the bodily feeling towards the particular object rather than some other completely different object. ${ }^{7}$

As an analysis in which emotional intentionality is partly constituted by response dispositions, I am sympathetic to Deonna and Teroni's position. Deonna and Teroni accurately recognise that in episodic emotions, bodily responses are set up to manage particular situations (i.e. the threat that the dog bears towards the individual) and so appealing to responses can potentially explain something about emotion intentionality. But as an analysis of emotional experience, I think their account is confused. Their key mistake is to assume that so long as you experience one's bodily responses as an emotional gestalt, you must experience them as directed towards the particular object. This is simply not the case. Deonna and Teroni seem to recognise that bodily feelings have emotional meaning, and one that is naturally complementary to the particular situational content of the emotion, but they are wrong to try and force that meaning into the experience of the situation. ${ }^{8}$ Bodily feelings most immediately tell us about the condition and capacities of one's body.

Overall, I find these accounts of feeling that (seem to) appeal to associations with particular external objects to be unsatisfying. Instead, I suggest that we give a more substantive characterisation of the awareness of the body itself.

\subsection{The emotional homunculus}

Consider again the case in which a car crash seems imminent. But let us now suppose that you feel all those bodily responses that are triggered to help get you out of danger. Intuitively, your bodily feelings carry a definite intentional content about the status of your body. Amongst other things, your muscles tense in 
anticipation of the impact. So we might say that bodily feelings represent a quite immediate relationship between the subject and his or her situation, in this case a feeling of one's body as being about to be hit or damaged.

Feeling this kind of relationship to the environment makes sense in relatively primitive cases of emotion, but one also experiences much the same pattern of bodily reactions in the financial fraud case. In such cases it is far less straightforward to say that you feel like you're about to be hit by something. The anticipated 'hit' is metaphorical. The same goes for most cases of bodily feelings in emotion. Anxiety, for instance, may be characterised by a bodily feeling of instability, yet one's body need not actually be unstable or even at risk of physical instability. One might rather be sitting in a chair on a sunny day rehearsing an important speech. What may be literally true in this case is that one is currently unable to cope with this task, and the failure to complete this task will harm one's reputation. Similarly, the feeling of emotional pressure involves a non-literal sense of something weighing upon you, or constricting you, where what is literally true is that increasing work demands are being placed upon you, and you recognise that you may not be able to meet those demands.

There is even experimental evidence that these non-literal meanings are more than merely fanciful interpretations of obscure bodily sensations. In one experiment (Zhong \& Leonardelli 2008), it was observed that people made to feel social exclusion judged the ambient temperature to be lower and showed a preference for warmer food. In a similar experiment (Zhong \& Liljenquist 2006), it was observed that people who read a first-person account of an act of sabotage showed a greater preference for antiseptic wipes. The authors conclude that the subjects felt a sense of dirtiness associated with guilt. It seems then that our common, non-literal understandings of bodily feelings are robust enough to guide relevant bodily responses and behaviours. 9

We can construe these non-literal representations of the bodily organism as somewhat analogous to those diagrams of the body homunculus, in which the body is spatially distorted according to the tactile sensitivity of its various parts (for instance, its hands and lips are huge compared to its skinny legs). An emotional representation of the homunculus can vary in even more extreme ways. It may seem relatively solid, large, dirty, rough or on fire. It is precisely these variations that are captured in stylised artistic depictions of the human body. Consider for instance the difference between Alberto Giacometti's and Henry Moore's sculptures. Both artists convey a sense of the human body that we can intuitively recognise as possible transformations of bodily feeling; to put it roughly-distended and brittle in the case of Giacometti, solid and smooth in the case of Moore. Consider also the case of non-vocal music. It has long been recognised that non-vocal music lacks the resources to represent particular situational content (e.g. Kivy 1999). Yet most listeners agree that music conveys specific emotions with intense vividness. A plausible suggestion is that music is managing to capture a sense of emotional bodily feeling rather than situational emotional content. This aligns well with contemporary 'persona' theories of musical expressivity (e.g. Levinson 2005; Robinson 2005; Cochrane 2011). 


\subsection{Emotional space}

At the same time, our emotional feelings give us a sense of being embedded within an 'emotional space'. One may feel that something heavy is weighing one down, or that one is floating in thin air. In this way the sense of emotional space is one in which certain actions seem encouraged. For instance, when we feel joy, the emotional space seems bright, boundless, even springy. We may then manifest this sense of emotional space by actually running, jumping or dancing around, or we may more generally interact with the actual environment in an energetic or springy manner. Phenomenologically speaking, our sense of emotional space may seem to overlay our sense of real space.

It is this sense of emotional space that I think gives us a clue to what is represented in emotional bodily feelings. In more psychologically oriented terms, the bodily feeling represents the affordances offered by own bodies in relation to the external environment. ${ }^{10}$ As was noted above with regards to mood, we may say that we display a certain dispositional attitude towards the world, but here we construe the attitude in more behavioural terms. The bodily feelings represent to us, at a quite general level, the potential or preparedness for certain environmental interactions. When one is having an emotion about a specific object, the bodily responses are in fact geared towards a specific environmental interaction. But lacking in themselves any information about the particular situation, the feelings of those responses represent the capacities or dispositions of the person related only in a very general way to the environment (an emotional space).

Thus metaphorical descriptions of bodily feeling capture in an intuitive and nuanced manner the various bodily capacities and dispositions for environmental interaction that are deployed in our emotional responses. Then when it comes to clarifying the subtly varying phenomenology of bodily feelings, it is helpful to appeal to a few abstract dimensions. For instance, in an earlier paper (Cochrane 2009), I delineated eight dimensions of emotional experience. These dimensions include positive-negative valence, power-weakness, certainty-uncertainty, a sense of social connectedness or isolation, and the overall temporal envelope of the feeling that convey qualities like duration and the sense of something upcoming or passing away. ${ }^{11}$ In that article I argued that these dimensions are sufficient for finely distinguishing emotional types. Here I claim that these dimensions also apply to bodily feelings, and so our feelings can equally allow us to identify very specific emotional states. For instance, the bodily feeling of fear generally involves a sense of weakness, where the onset of that weakness could appear gradually (anxiety), or more suddenly (panic). Meanwhile, sadness also seems to involve the sense of weakness, yet differing temporally from fear in that one senses not losing stability or anticipating impact so much as having fallen or having been hit.

Overall, our emotional bodily feelings constitute a rich resource of vivid and nuanced content about our status. Moreover, while these feelings seem intuitively to go beyond the literal condition of the bodily organism, it can still be the case that our status is accurately represented. The fraudulent bank transactions really do put me in a vulnerable situation with regards to my legal and financial status, and so it 
is quite appropriate that I feel vulnerable when placed in that personal context. This content is conveyed by means of an intuitive bodily sense of fragility or instability. And when we look closer, we can understand this feeling as representing a reduced capacity for control over one's environment and a disposition towards self-protecting behaviours.

\subsection{Distinguishing emotional bodily feelings}

We are now in a position to distinguish emotional bodily feelings both from the emotional awareness of situations and from non-emotional bodily feelings. First, we should note that both emotional bodily feelings and the emotional awareness of situations are relational in character. As mentioned in Section 2.2, the experience of the situation is implicitly relational since to see an object as threateningly looming is for one's body to be oriented towards it in a certain way. However, situational phenomenology focuses centrally on the particular object of the emotion. Meanwhile, emotional bodily feelings are relational in the sense that one experiences certain possibilities for interaction. However, the environment is represented in a peripheral and very abstract way. It is the condition and capacities of the body that are central and particular. Thus while both sorts of intentional experience are relational, there is a significant difference in focus. Another significant difference is that the situational phenomenology is essentially a passive representation of how things stand, where the emotional bodily feeling is representing the active powers of body to respond. This difference has implications for the possible function of emotional bodily feelings, as I will discuss in the following section.

Let us now distinguish emotional bodily feelings from feelings of bodily conditions such as tiredness, hunger and nausea that intuitively lack emotional meaning. When one is hungry, one can attend to the condition of one's body without it saying anything in particular about one's general response capacities. This suggests three rough conditions for emotional bodily feelings: First, emotional bodily feelings are experienced as relational in character, as giving one a sense of emotional space or generalised environmental affordances. Second, emotional bodily feelings tend to be experienced as a state of the whole person, rather than some isolated bodily component. Third, emotional bodily feelings tend to be experienced as irruptive rather than routine. Typically, feelings like hunger and tiredness occur predictably at certain times of the day as part of our ordinary bodily maintenance cycle.

I must emphasise that these conditions provide only a vague boundary. There may be emotional bodily feelings that are acute and routine (for instance, the actor feels butterflies in his stomach every single time he goes on stage). Some varieties of non-emotional feeling also seem to fit the conditions (consider for instance, a sudden and powerful craving for pizza). However, we may have reasons for thinking that a difference of degree is appropriate here. First, because bodily feelings are not necessary to emotional states, we need not expect a sharp distinction between bodily feelings of an emotional and non-emotional kind. ${ }^{12}$ Second, a close relationship between moods and bodily conditions like tiredness and hunger is widely 
recognised. We are apt to blame the emergence of a mood on physical tiredness, and we know that moods can be easily manipulated with bodily intoxicants like drugs and alcohol.

Nevertheless, the distinctive representational force of emotional bodily feelings suggests that a distinctive representational act occurs. For this reason, I propose that a definitive distinguishing feature of emotional bodily feelings is that the individual applies an emotion concept to his or her bodily feelings. What the three conditions outlined above do is just tell us roughly what the emotion concept amounts to. That is, the individual deploys a concept of emotional space, or generalised behavioural affordances in cognitively organising the feelings of his or her bodily condition. This concept need not be symbolically articulated. I think it more likely to be a prototype of how one tends to behave when undergoing an emotional state. ${ }^{13}$ It moreover need not be gained from a sophisticated self-reflective understanding of one's prior experience of emotion. It may just be a concept we characteristically deploy when guiding an emotional response.

One reason for appealing to a conceptual act comes from the claim I made in Section 2.4 that emotional bodily feelings may be generated either by lingering bodily responses, or emergent bodily conditions. In cases where bodily feelings reflect bodily responses that have been triggered by a prior emotional appraisal, it would be fair to say that those bodily feelings carry information about the emotional state of the individual. That might be enough to differentiate emotional bodily feelings from non-emotional bodily feelings. However, cases where a distinctive bodily condition is aroused prior to the emotional appraisal of a particular situation cannot make use of this strategy. Emergent cases are more effectively explained by appeal to a conceptual act.

To explain, recall that in the case of depression, the individual's bodily condition was close enough to a distinctive sort of emotional response to dispose them towards congruent emotional appraisals. The individual does not just more readily trigger certain bodily responses, they more readily remember and attend to sad situations. But why should memories and appraisals of loss become more salient? The easiest way to explain this is that the individual at least implicitly recognises that they feel the way they do when they feel sad; they conceptualise the feeling of their bodily capacities in a certain way.

Thus, in addition to capturing the distinctive representational force of bodily feelings, the appeal to conceptualisation as a key condition for emotional bodily feeling can explain emergent condition cases, and equally apply to lingering feeling cases. If the reader does not acknowledge emergent condition cases, this advantage will be less impressive. Such a reader may instead prefer the idea that emotional bodily feelings carry information about prior emotional appraisals as mentioned above. However, the reader would still need to make sense of the way we experience bodily feelings as intentionally meaningful; reaching beyond the mere sensation of the body. I find it hard to see how this could be sustained, unless one alternatively appeals to a definite association with the emotional appraisal (as Goldie 2000 and Deonna and Teroni 2012 seem to do). But then it looks like establishing a semantic relationship between the feeling and the 
situational appraisal is still needed. So at least with regards to parsimony, there's no advantage of this approach over the conceptual approach I have described. And to reiterate the point I made with regards to Goldie's model, there's some disadvantage in appealing to an indirect attribution of meaning to the feeling that doesn't focus on the characteristics of the body itself.

Meanwhile, I am inclined to think that if a person claims to feel depressed or hopeless about their personal status, and they display the usual bodily profile of sadness, we should believe them, even if they have not appraised some specific loss prior to making this claim. Yet at the same time, we should not allow that an individual can infallibly decide whether or not they're having an emotional bodily feeling. Karen Jones (2008: 269-270) nicely illustrates our fallibility with two examples from fiction. In the novel Oranges are not the only fruit, the mother mistakes a stomach ulcer for feelings of love. In Brokeback Mountain, Ennis misinterprets intense yearning as food poisoning. This fallibility suggests the need for an additional condition that can specify when it is warranted, or appropriate to conceptualise one's bodily feelings under an emotional gestalt.

My proposal is that if one's overall bodily condition does in fact correspond to the pattern of bodily responses that is standardly aroused by a certain emotion, then the individual is warranted to conceptualise the feelings of their bodily condition as the state of self most complementary to that emotional state. That is, $x$ is an emotional bodily feeling when (1) the individual conceptualises (implicitly or explicitly) bodily feelings as emotional, and (2) the individual is in a bodily condition that matches the typical condition of their body when undergoing an emotion about a particular situation.

Conditions like these are analogous to conditions that are plausibly given for pictorial representation. That is, a visual pattern is a picture of a tree if (1) the viewer deploys a recognitional concept of a tree with respect to the visual pattern and (2) the visual pattern resembles the outline shape of a tree (cf. Hopkins 2005). In both emotions and pictures, there is both something artificial and something quite natural about their representational status.

Thus Ennis inappropriately construes his bodily feelings because his feelings do not carry information about the biological condition of indigestion. He realises later on that his feelings are more appropriately conceptualised as emotional, because they most closely resemble the feelings you get when your bodily response is aimed at renewing contact with your beloved. To be clear, prior to him conceptualising them as emotional (assuming this is not already done unconsciously) the bodily feelings did not independently represent an emotional state of self. Rather they could justifiably have been used to do so.

The mother meanwhile was not actually feeling a bodily condition that corresponded with a disposition to renew contact with her lover (the condition would not have been impacted much had she succeeded). She was simply confused about the kinds of patterns of bodily affordances that love typically involves (at least as we ordinarily understand the patterns of feeling that love involves). ${ }^{14}$

It strikes me that recognising the somewhat artificially representational nature of emotional bodily feeling might accommodate to some degree 'core affect' 
theories of emotion in psychology (e.g. Russell \& Barrett 1999). According to these theories, our non-interpreted emotional responses only intrinsically possess a certain degree of valence and a certain degree of arousal. The (culturally influenced) interpretation of the individual then reconceptualises core affect, plus the awareness of the situation, into the various discrete emotion types that we recognise. Now, I am not sympathetic to the denial of natural emotion types corresponding to distinctive ways of appraising situations and distinctive patterns of response. However if taken to focus only on bodily feelings and not the emotional experience of situations, it may be right to say that without some conceptual framework to deliver representational meaning, bodily feelings only present a certain degree of arousal in themselves. ${ }^{15}$

\subsection{The function of emotional bodily feelings}

Now we know what emotional bodily feelings are, there is one striking question that remains outstanding: Why do we experience emotional bodily feelings? What is their function?

There is evidence that interoceptive sensitivity bears a general correlation with emotional sensitivity (e.g. Herbert et al. 2007; Calì et al. 2015). ${ }^{16}$ However, I think it most plausible that the additional intentional content provided by emotional bodily feelings is a form of self-monitoring. Emotions involve a fairly complex causal process, and it is typical for us to be able to attend to the different aspects of our bodily processes, particularly as we learn more about how our bodies function. It also makes sense from an evolutionary point of view that we are endowed with the ability to monitor our bodily responses (as opposed to sheer bodily sensation). By giving us a sense of our bodily capacities or powers, such monitoring contributes to planning. For example, if one tenses in anticipation of being hit, one can roughly judge the extent to which one's body is strong enough to withstand the blow. In a similar way, it is plausible that emotional self-monitoring is a key distinctive capacity that bodily feelings add to our everyday emotional experiences. By giving us a sense of our behavioural stance or dispositions, emotional bodily feelings contribute significantly to the planning and regulation of our emotionally driven behaviours.

If $I^{\prime} m$ right about the self-monitoring function of bodily feelings, this may also explain some variations in the responses that we have towards certain emotionally arousing situations. I am thinking in particular of the case of fear. Being able to estimate one's physical capacity to deal with a threat could make a decisive difference between triggering a freeze response as opposed to flight response. That is, if one recognises that one lacks the capacity to escape a threat, then the best behavioural strategy may be to freeze or play dead. It seems to me that this choice most plausibly follows the initial activation of the impulse to flee which is then inhibited, rather than failing to activate the flight response at all (cf. Kever et al. 2015). Indeed, if freezing doesn't work, the flight response may be best held in readiness. I take these considerations to align very nicely with what psychologists such as Klaus Scherer (2005) call appraisals of 'coping potential'. I even agree with 
Scherer that this sort of calculation should temporally follow initial emotional appraisals (e.g. Scherer takes calculations of 'goal relevance' to be sequentially prior).

A final implication of this view of bodily feelings is potentially quite profound. In taking us beyond the immediate impact upon our bodies and representing the subject as the centre of agency, as temporally enduring and spatially oriented, bodily feelings in emotions constitute a basic form of self-consciousness. Given how early they are likely to appear in our lives, bodily feelings may even be some of the first mental states in which we become aware of ourselves as sources of agency extending into future, and as distinct from other persons. For these reasons, I summarise what our bodily feelings represent as 'states of self'. In everyday emotional experience, these states of self are experienced alongside, and as more or less in alignment with the emotional experience of particular situations. ${ }^{17}$

\section{The Emotions Debate}

The final points I would like to make in this paper concern its relevance to ongoing debates in the theory of emotions. Making a distinction between bodily feelings and object-directed emotions helps to explain the different ways that people conceptualise their emotions. The psychologist James Laird (2007) presents evidence from a large number of experiments that some people tend to recognise their emotions in terms of the context situations in which they are embedded, where others reflect more on their bodily feelings. Of course, this doesn't rule out the possibility that everyone is just wrong about how emotions are in fact constituted. But when it comes to how emotions are experienced, we may be more willing to accept a possible bifurcation of attention.

One striking piece of evidence in favour of Laird's claim is the observation that some people are more susceptible than others to what is known as the 'facial feedback' effect. ${ }^{18}$ This is a phenomenon in which adopting facial expressions characteristic of certain emotions leads to both self-reports, physiological responses and behaviours indicative of those emotions. It seems that some people are prone to associate certain expressive reactions with the full-blooded emotional state, even without explicitly noting the fact, where others look more towards the situation to assess what emotion they are in. That is, it seems that some people more readily conceptualise their bodily feelings under an emotional gestalt.

The facial feedback effect might be thought to indicate that bodily reactions alone are sufficient for emotional states, independent of any representation of the way some situation impacts upon one's concerns. Our analysis should be a bit more complex than this however. We can admit that facial feedback may be sufficient to generate an emotional bodily feeling. These cases resemble the kinds of long-term affective states lacking a prior appraisal that I described in Section 2.4. However, they are better described as moods than full-blown emotions. Then if the individual identifies some object as the target of their bodily feeling (as is often 
encouraged in the experiments Laird reports), they might now be said to be undergoing an emotional illusion. But if the cognitive bias generated by the mood leads them to actually appraise an object in a manner congruent with their bodily feeling, then we have a bona fide emotional state.

The fact that people split into two broad groups in their conceptualization of emotions goes, I think, some way towards explaining the long-standing theoretical debate between those that support bodily feeling-based models of emotion and those that support situation appraisal-based models. Psychologists and philosophers may be driven by their intuitive attentional bias towards one or other aspect of emotional experience to prioritise that aspect in their theorising. If emotional experiences have dual intentional content, we can allow that both parties are picking up on an important aspect of emotional experience. We can also understand why it is so hard to pin down the intentional nature of emotions.

Let me be clear, I do not think emotions have to be conscious at all. I have not tried to justify this claim in this article, since my arguments for the double intentionality of emotional experience do not rely on it. ${ }^{19}$ Yet it is worth mentioning that such a view indicates that neither the emotional experience of a situation, nor the emotional bodily feeling need be more essential when it comes to characterising emotional experience. I have not said much about the emotional experience of particular situations here. I assume that we emotionally appraise particular situations and that this process can happen consciously. And since I have claimed that the emotional experience of bodily responses requires an additional step of conceptual organisation, it may be that the emotional experience of a situation is less demanding and accordingly more ubiquitous. But since I hold that emotions always involve both an appraisal of a situation and a bodily response, the experience of either is sufficient for an emotional experience, and both are probably present in the average case.

\section{Conclusion}

I have argued that the experience of bodily feelings, while not strictly necessary to emotions, contributes intentional content to emotional experiences when it occurs. Our feelings tell us something about our current 'state of self' —as solid and secure, or weak and contingent, enduring or transient. And although this content is represented intuitively by means of a non-literal sense of one's bodily condition in relation to an 'emotional space', the status represented can be entirely warranted. It is to be analysed as an awareness of the disposition of the body towards interacting with the environment in a certain way.

Overall, by appeal to the double intentionality of emotions, we can allow for the possibility that a subject can be aware of his or her feelings while simultaneously unaware of any particular situation to which his or her emotion is directed, and vice versa. We can also make sense of some of the difficulties in characterising emotional intentionality, and the general division between appraisal-based and bodily feeling-based models of emotion. 
Tom Cochrane

Department of Philosophy, University of Sheffield

UK

thomas.cochrane@gmail.com

\section{NOTES}

$1 \quad$ See instead Salmela (2011); Deonna and Teroni (2012): Ch. 6); Barlassina \& Newen (2013). See also Hatzimoysis (2003) who argues that perception is not transitive such that by perceiving one thing (i.e. bodily changes by means of interoception) you can then also perceive its causal trigger (the offence).

2 This is not to be confused with cases where blindsight patients are sometimes emotionally aroused by images presented to the neglected portion of their visual field (described as 'blindfright' by Scarantino 2010). In such cases, patients report conscious emotional feelings, yet cannot identify the cause or target of their emotion. Similar phenomena occur in cases of alexithymia, as well as experiments in which arousing stimuli are presented too quickly for conscious recognition. These sorts of cases correspond better to the variety of moods I describe below. I would not however rule out the possibility that some severe cases of alexithymia could correspond to the condition I describe in this section.

3 This basically corresponds to Jesse Prinz's (2004) model of emotions, which allows for unconscious cases.

4 For a detailed discussion of this dispositional variety of mood, see Siemer 2009. For a discussion of moods as patterns of vigilance, see Price 2006.

5 Though it is worth noting that even with regards to conceptually construed sources of harm, our bodily responses serve to orient us towards the threat represented. Heightened arousal and attention directly sustain our more cognitively sophisticated responses, and as in the driver case, our bodily responses quite generally track the seriousness and urgency of the situation.

6 Deonna and Teroni claim that formal objects, which they call 'evaluative properties' play a justifying role for the emotion, but are not what the emotion itself is directed at.

7 Cf. Barlassina \& Newen's criticism of Prinz's model (2013: section 3.4).

8 In their reliance on bodily feelings, Deonna and Teroni also cannot allow for the driver cases described in Section 2.1. Although Deonna and Teroni briefly allude to Goldie's example (2012: 87), they claim that in the aftermath of narrowly avoiding the crash, the driver experiences his various bodily responses atomistically, and not as a meaningful gestalt. As mentioned above when describing the financial fraud case, such an atomistic perspective is possible, but not necessary.

9 These considerations align well with the theory of conceptual metaphor defended by Lakoff and Johnson (1980), which argues that our metaphorical forms of speech (e.g. 'he hit me with the news') are rooted in sensory-motor experience. If our emotions are accompanied by certain typical patterns of bodily changes, we can expect a fair amount of agreement about which metaphors are appropriate for which feelings.

10 Occasionally, Prinz makes comments that resemble this account of bodily feelings when, for instance, he compares emotions to affordances (2004: 228). In this case, he references Gibson's notion of positive and negative affordances (1979: 137) but note that Gibson doesn't flesh out this claim very much either. More recently, Rebekka Hufendiek (2016) has proposed a view of emotional experience that appeals to the sense of affordances. However, 
like other somaticist views, Hufendiek places bodily feelings too central to the core of emotional representation for my liking.

11 In that article, I also specify a dimension of freedom-constraint, which more recently I've decided to drop as unnecessary. I also specify a dimension of 'generality' that applies more to differentiating emotions from moods and long-term sentiments, rather than differentiating within the field of emotions or bodily feelings.

12 Meanwhile, a sharper boundary can be drawn between the emotions and affective states such as pain, hunger and tiredness. I do not have the space to fully outline this view here, but the basic idea is that while pains and pleasures are directed at immediate impacts upon the body, our emotions are essentially contextual in intentional content. For instance, fear is paradigmatically directed at future circumstances, regret is directed at ways things could have been, and jealousy concerns our social attachments. I have more to say on this subject in a book I am currently preparing on emotions.

13 For a discussion of prototype theories of concepts, see Laurence \& Margolis (1999). I take it that this kind of concept is relatively undemanding, and so should be available to various non-human animals. However, it is more demanding than simply having an emotion, so there may be emotion-bearing animals that lack emotional bodily feelings.

14 I am open to the possibility that whether the concept 'love' is appropriately applied to a pattern of bodily feelings may involve some social-externalist deference to how one's linguistic community categorises emotions. For a very interesting defence of this notion, see Campbell (1997).

15 Cases of pain asymbolia (e.g. Klein 2015) indicate that the sensation of pain and its badness can be distinguished, so even valence may not be as presentational as the core affect theorists imply.

16 Interoceptive sensitivity has also been found to facilitate reflective reappraisal of one's emotions (Füstös et al. 2013), as well as the capacity to detect emotions in others (Terasawa et al. 2014).

17 Cf. a comparable view outlined by Gallese \& Sinigaglia (2010). Jan Slaby (2012) also explores the ways that emotions disclose a sense of self that is simultaneously the sense of ability. However, he does not distinguish the intentionality of bodily feeling from the intentionality of emotions themselves. Also comparable is Matthew Ratcliffe's (2008) notion of 'existential feelings'. These are variations in one's basic orientation to the world, including an intuitive conception of one's self, and are intended to capture phenomenological aspects of various psychiatric disorders ranging from depression to Cotard's syndrome. The main difference between this account and my own is that on my account bodily feelings can include both pervasive background feelings of the kind Ratcliffe describes, as well as the more transient and less profound feelings that accompany episodic emotions.

18 It should be noted that given a recent replication failure of one of the original experiments supporting facial feedback (Wagenmakers et al. (2016) replicating Strack, Martin \& Stepper 1988), this phenomenon is currently under doubt. However, Laird draws together a wide variety of data confirming the existence of this effect, in addition to making some useful qualifications about individual variability.

19 The best empirical evidence I've seen for genuinely unconscious emotion (as opposed to misinterpreted moods) is Winkielman and Berridge (2015). Here they show differences in behaviour as a result of masked emotional stimuli (pictures of happy and angry faces) while also confirming that the participants report no emotion at all, even when their attention is drawn towards how they are feeling. 


\section{REFERENCES}

Barlassina, L. and Newen, A. (2013), 'The Role of Bodily Perception in Emotion: In Defense of an Impure Somatic Theory', Philosophy and Phenomenological Research, 89: 637-678.

Calì, G., Ambrosini, E., Picconi, L., Mehling, W. E. and Committeri, G. (2015), 'Investigating the Relationship Between Interoceptive Accuracy, Interoceptive Awareness, and Emotional Susceptibility', Frontiers in Psychology, 6: 1-13.

Campbell, S. (1997), Interpreting the Personal: Expression and the formation of feelings. Ithaca: Cornell University Press.

Cochrane, T. (2009), 'Eight Dimensions for the Emotions', Social Science Information, 48: $379-420$.

- (2011), 'Using the Persona to Express Complex Emotions in Music', Music Analysis, 29: 264-275.

Deonna, J. A. and Teroni, F. (2012), The Emotions: A Philosophical Introduction. Oxford: Routledge.

Füstös, J., Gramann, K., Herbert, B. M. and Pollatos, O. (2013), 'On the embodiment of emotion regulation: interoceptive awareness facilitates reappraisal' Social cognitive and affective neuroscience, 8: 911-917.

Gallese, V. and Sinigaglia, C. (2010), 'The Bodily Self as Power for Action', Neuropsychologia, 48: 746-755.

Gibson, J. (1979), The ecological approach to human perception. Boston: Houghton Mifflin.

Goldie, P. (2000), The Emotions: A Philosophical Exploration. Oxford: Oxford University Press.

Gunther, Y. H. (2004), 'The Phenomenology and Intentionality of Emotion', Philosophical Studies, 117: 43-55.

Herbert, B. M., Pollatos, O. and Schandry, R. (2007), 'Interoceptive sensitivity and emotion processing: An EEG Study', International Journal of Psychophysiology, 65: 214-227.

Hufendiek, R. (2016), Embodied Emotions: A Naturalist Approach to a Normative Phenomenon. New York: Routledge.

James, W. (1884), 'What is an Emotion?' Mind, 9: 188-205.

- (1890), The Principles of Psychology, Vol. 2 vols. New York: Henry Holt.

Jones, K. (2008), 'How to Change the Past', in C. Mackenzie and K. Atkins (eds) Practical Identity and Narrative Agency. London: Routledge.

Laird, J. (2007), Feelings: The Perception of Self. Oxford: Oxford University Press.

Lakoff, G. and Johnson, M. (1980), Metaphors We Live By. Chicago: University of Chicago Press.

Laurence, S. and Margolis, E. (1999), 'Concepts and Cognitive Science', in E. Margolis and S. Laurence (eds) Concepts: Core Readings. Cambridge, MA: MIT Press.

Levinson, J. (2005), 'Musical Expressiveness as Hearability-As-Expression', in M. Kieran (ed.) Contemporary Debates in Aesthetics and the Philosophy of Art. Oxford: Blackwell.

Kever, A., Pollatos, O., Vermeulen, N. and Grynberg, D. (2015), 'Interoceptive Sensitivity Facilitates both Antecedent- and Response-Focused Emotion Regulation Strategies', Personality and Individual Differences, 87: 20-23.

Kivy, P. (1999), 'Feeling the Musical Emotions', British Journal of Aesthetics, 38: 1-13.

Klein, C. (2015), 'What Pain Asymbolia Really Shows', Mind, 124: 493-516.

Prinz, J. (2004), Gut Reactions: A Perceptual Theory of Emotion. Oxford: Oxford University Press.

Price, C. (2006), 'Affect Without Object: Moods and Objectless Emotions', European Journal of Analytic Philosophy, 2: 49-68.

(C) 2017 John Wiley \& Sons Ltd 
Ratcliffe, M. J. (2008), Feelings of Being: Phenomenology, Psychiatry, and the Sense of Reality. Oxford: Oxford University Press.

Robinson, J. (2005), Deeper Than Reason: Emotions and its Role in Literature, Music, and Art. Oxford: Oxford University Press.

Russell, J. A. and Barrett, L. F. (1999), 'Core Affect, Prototypical Emotional Episodes, and Other Things Called Emotion: Dissecting the Elephant', Journal of Personality and Social Psychology, 76: 805-819.

Salmela, M. (2011), 'Can Emotion Be Modelled on Perception?' Dialectica, 65: 1-29.

Scarantino, A. (2010), 'Insights and blindspots of the cognitivist theory of emotions' The British Journal for the Philosophy of Science, 61: 729-768.

Scherer, K. (2005), 'What are Emotions and How can They be Measured?' Social Science Information, 44: 695-729.

Siemer, M. (2009), 'Mood Experience: Implications of a Dispositional Theory of Moods', Emotion Review, 1: 256-263.

Slaby, J. (2012), 'Affective Self-Construal and the Sense of Ability', Emotion Review, 4: 151-156.

Solomon, R. C. (2007), True to our Feelings: What our Emotions are Really Telling Us. Oxford: Oxford University Press.

Strack, F., Martin, L. L. and Stepper, S. (1988), 'Inhibiting and Facilitating Conditions of the Human Smile: A Nonobtrusive Test of the Facial Feedback Hypothesis', Journal of Personality and Social Psychology, 54: 768-777.

Terasawa, Y., Moriguchi, Y., Tochizawa, S. and Umeda, S. (2014), 'Interoceptive Sensitivity Predicts Sensitivity to the Emotions of Others', Cognition and Emotion, 28: 1435-1448.

Wagenmakers, E.-J., Beek, T., Dijkhoff, L., Gronau, Q. F., Acosta, A., Adams, R. B., Jr., Albohn, D. N., Allard, E. S., Benning, S. D., Blouin-Hudon, E.-M., Bulnes, L. C., Caldwell, T. L., Calin-Jageman, R. J., Capaldi, C. A., Carfagno, N. S., Chasten, K. T., Cleeremans, A., Connell, L., DeCicco, J. M., Dijkstra, K., Fischer, A. H., Foroni, F., Hess, U., Holmes, K. J., Jones, J. L. H., Klein, O., Koch, C., Korb, S., Lewinski, P., Liao, J. D., Lund, S., Lupiáñez, J., Lynott, D., Nance, C. N., Oosterwijk, S., Özdoğru, A. A., Pacheco-Unguetti, A. P., Pearson, B., Powis, C., Riding, S., Roberts, T.-A., Rumiati, R. I., Senden, M., Shea-Shumsky, N. B., Sobocko, K., Soto, J. A., Steiner, T. G., Talarico, J. M., van Allen, Z. M., Vandekerckhove, M., Wainwright, B., Wayand, J. F., Zeelenberg, R., Zetzer, E. E. and Zwaan, R. A. (2016), 'Registered Replication Report: Strack, Martin, \& Stepper (1988)', Perspectives on Psychological Science, 11: 917-928.

Winkielman, P. and Berridge, K. (2015), 'Unconscious Emotion', Current Directions in Psychological Science, 13: 120-123.

Yiend, J. (2009), 'The Effects of Emotion on Attention: A Review of Attentional Processing of Emotional Information', Cognition $\mathcal{E}$ Emotion, 24: 3-47.

Zhong, C. and Leonardelli, G. J. (2008), 'Cold and Lonely: Does Social Exclusion Literally Feel Cold?' Psychological Science, 19: 838-842.

Zhong, C. and Liljenquist, K. (2006), 'Washing Away Your Sins: Threatened Morality and Physical Cleansing', Science, 313: 1451-1452. 